Review Article

www.ijrap.net (ISSN:2229-3566)

\title{
DIFFERENT MODERN TECHNIQUES USED IN CHURNA KALPANA: A REVIEW
}

Jagadeesh G Mitti *

Professor, Department of Rasa Shastra and Bhaishajya Kalpana, JSS Ayurveda Medical College and Hospital, Mysore, Karnataka, India

Received on: 18/05/20 Accepted on: 07/08/20

*Corresponding author
E-mail: drmitti@yahoo.co.in

DOI: $10.7897 / 2277-4343.1105157$

\section{ABSTRACT}

To prepare any formulation in bulk quantity it needs a machine. The machines which manufacture the formulations in a bulk quantity will work on the basis of modern techniques. These techniques can be adopted to prepare different dosage forms through their method of preparations. Churna is also one among the different dosage forms which is having versatile usage and need to be prepared in bulk quantity. To achieve this, different modern methods like size reduction, size separation and mixing of powders and techniques viz. cutting, compression, impact, attrition and combined effect of impact and attrition are adopted, along with this sieving and mixing techniques are also adopted. To assure the quality of churna kalpana physico chemical analysis should be done like fineness of Particles, Presence of Heavy Metals, Test for microbial contamination etc.

Keywords: Churna, Size reduction, Size separation, Cutting, Compression, Impact, Attrition Agitation, fineness of Particles, Presence of Heavy Metals.

\section{INTRODUCTION}

Success in Ayurvedic treatment greatly depends on the quality of medicines used. In present scenario, physician does not have a direct control over the preparations of medicine. Ayurvedic pharmaceutical industry is having a substantial part playing in the commercial market and also manufacturing the number of formulations in a bulk quantity with different dosage forms.

To prepare any formulation in bulk quantity it needs a machine. The machines which manufacture the formulations in a bulk quantity will work under modern techniques. These techniques will be adopted to prepare different dosage forms through their method of preparation without affecting the basic principles of Bhaishajya kalpana.

Churna Kalpana is also one among the different dosage forms which is having versatile usage and need to be prepared in bulk quantity. Fine powder obtained after thoroughly pounding and filtering the completely dry drugs is called as churna. ${ }^{1}$

The different techniques adopted to prepare Churna kalpana

- Size reduction

- Size separation

- Mixing of powders

\section{Size reduction}

Size Reduction is a process of reducing drugs into smaller pieces, coarse particles or fine powder. This technique can be correlated with Mardana Samskara of churna process.

\section{Methods of Size Reduction}

1. Cutting

2. Compression

3. Impact
4. Attrition

5. Combined effect of impact and attrition ${ }^{2}$

\section{Cutting}

Cutter mill is used for cutting the drugs in bulk quantity.

Principle: size reduction is done by cutting with the help of sharp knives

Uses: mill is used to obtain a coarse degree of size reduction of soft materials. ${ }^{3}$

\section{Compression}

Roller mill is used for crushing and drugs on large scale.

Principle: material is crushed by the application of pressure.

Uses: Roller mill is used for crushing and cracking of seeds and to crush the soft drugs ${ }^{4}$.

\section{Impact}

Hammer mill and disintegrator are used to reduce the size of drugs.

Impact occurs when the materials is more or less stationary and is hit by an object moving at high speed or when the moving particles strikes a stationary surface. The material breaks into small pieces in both the cases.

\section{Hammer mill}

Principle: It works on the principle of impact as explained in above paragraph.

Uses: Hammer mill is used for production of intermediate grades of powder from almost all types of substances except sticky materials which choke the screen.

\section{Disintegrator}

Principle: It also acts on principle of impact. 
Uses: It is used to powder all types of drugs including very hard drugs.

Hammer mill and disintegrator working on the same principle i.e. impact but, the only difference is disintegrator will not produce any air pollution as compared with hammer mill.

\section{Attrition}

In Attrition pressure is applied on the material as in compression but, the surfaces are moving relative to each other, resulting in shear forces which break the particles.

Here also roller mill is used on a large scale of drugs size reduction. ${ }^{6}$

\section{Combined Impact and Attrition}

Ball mill and Fluid energy mills are used to reduce the size of the drugs in a bulk quantity.

\section{Ball mill}

Principle: Ball mill works on the principle of impact and attrition Uses: It is used to grind brittle drugs to fine powder

\section{Fluid energy mill}

Principle: It works on the principle of impact and attrition Uses: It is used to grind heat sensitive drugs to fine powder and also used to grind those drugs in which high degree of purity is required. ${ }^{7}$

\section{Size separation}

The process of size reduction is followed by size separation of the powdered drug. During the process of size reduction, it is not possible to obtain the particles of uniform size. Hence a special technique is used to separate particles of specified size which is known as 'Process of size reduction'. This technique can be correlated with Seevana Samskara of churna process.

Size separation process may be applied to the measurement of the particle size, in which the proportion of each size of particle in a sample is determined and data is utilized to control raw material or to maintain the quality of manufactured product.

Before going to explain about method of size separation it is essential to know about the different grades of powder.

The Indian pharmacopoeia specifies 5 grades of powder on the basis of nominal mesh aperture size of the sieve through which powder is able to pass. ${ }^{8}$ They are as follows

1. Coarse powder (10/44)

2. Moderately coarse powder $(22 / 60)$

3. Moderately fine powder $(44 / 85)$

4. Fine powder (85)

5. Very fine powder (120)

\section{Sieves}

Sieves are constructed from wire cloth with square meshes, woven from wires of brass, bronze, stainless steel.

\section{Standards of sieves}

Sieves used for Pharmacopoeial testing must specify the following factors.
1. Number of sieves

2. Normal size aperture

3. Normal diameter of the wire

4. Approximate $\%$ sieving area

5. Tolerance average aperture size

\section{Sieving}

Sieving is the method which is used for the technique of size separation after size reduction of powders.

In this method different grades of powders are separated using sieves of desired number. The degree of fineness of a powder is known with the help of sieve number through which the powder material is passed. Sieves are numbered in order to identify them from each other.

Mechanical sieving machine is used for size separation on a large scale. $^{9}$

\section{Electromagnetic sieving machine}

The working of mechanical sieving device is based on any of the following methods.

1. Agitation

2. Brushing

3. Centrifugal

\section{Mixing of Powders}

Mixing is the technique which is used to mix two or more than two substances. Perfect mixing is that in which each particle of one material lies as nearly adjacent as possible to a particle of other material.

Mixing of powders is one of the common pharmaceutical operations which is used in the preparation of many types of formulations such as tablets, capsules etc. ${ }^{10}$

\section{Machines used for mixing of powders}

On a large scale the following machines are used for mixing of powders ${ }^{11}$.

1. Tumbler mixer

2. Double cone mixer

3. Agitated Powder mixer

4. Air mixer

\section{Quality control of Churna Kalpana}

Physico chemical Analysis is essential for Churna kalpana to assure the quality. They are as mentioned below.

1. Organoleptic Characters:

- Colour

- Odor

- Taste

- Consistency

2. Loss on drying at $110^{\circ} \mathrm{C}$

3. Determination of water-soluble extractive

4. Determination of Alcohol soluble extractive

5. Determination of fineness of particles

6. Determination of Total Ash

7. Determination of Acid insoluble Ash

8. Determination of Mercury 
9. Determination of Arsenic

10. Determination of Lead

11. Determination of Cadmium

12. Test for Microbial contamination

13. Test for Pesticidal Residue ${ }^{12}$

\section{CONCLUSION}

In the present scenario it is necessary to adopt the modern techniques and quality control measures to manufacture and analyze different dosage forms to get good quality medicines to meet the global demand. These techniques will help in improving the SOP and SMP of Churna Kalpana. These techniques should be adopted without affecting the basic principles of Bhaishajya Kalpana.

\section{REFERENCES}

1. Sharangadhara, Sharangadhara Samhita, Madhyama Khanda Chapter 6, Shloka No 1, Edited by Acharya Shri Radhakrishna Parashara, $4^{\text {th }}$ edition, Published by Swati Enterprises, Nagpur; 1994. p. 247.

2. Bentley, Textbook of Pharmaceutics, Edited by E A Rawlins, $8^{\text {th }}$ edition, Published by Bailliere Tindal, UK, Reprint (All India traveler book seller, Delhi), Chapter 17; 2004. p. 244.

3. R M Mehta, Pharmaceutics, Vol $1,3^{\text {rd }}$ edition, Reprint, Published by Vallabh Prakashan, Delhi, Chapter 5; 2003. p. 96.

4. R M Mehta, Pharmaceutics, Vol 1, $3^{\text {rd }}$ edition, Reprint, Published by Vallabh Prakashan, Delhi, Chapter 5; 2003. p. 97.
5. R M Mehta, Pharmaceutics, Vol 1, $3^{\text {rd }}$ edition, Reprint, Published by Vallabh Prakashan, Delhi, Chapter 5; 2003. p. 98-99.

6. R M Mehta, Pharmaceutics, Vol 1, $3^{\text {rd }}$ edition, Reprint, Published by Vallabh Prakashan, Delhi, Chapter 5; 2003. p. 99.

7. R M Mehta, Pharmaceutics, Vol 1, $3^{\text {rd }}$ edition, Reprint, Published by Vallabh Prakashan, Delhi, Chapter 5; 2003. p. 100.

8. R M Mehta, Pharmaceutics, Vol 1, $3^{\text {rd }}$ edition, Reprint, Published by Vallabh Prakashan, Delhi, Chapter 6; 2003. p. 108-110.

9. R M Mehta, Pharmaceutics, Vol 1, $3^{\text {rd }}$ edition, Reprint, Published by Vallabh Prakashan, Delhi, Chapter 6; 2003. p. 111-112.

10. Bentley, Textbook of Pharmaceutics, Edited by E A Rawlins, $8^{\text {th }}$ edition, Published by Bailliere Tindal, UK, Reprint (All India traveler book seller, Delhi), Chapter 17; 2004. p. 250.

11. R M Mehta, Pharmaceutics, Vol 1, $3^{\text {rd }}$ edition, Reprint, Published by Vallabh Prakashan, Delhi, Chapter 7; 2003. p. 119-121.

12. API, Vol-1, Part 2, $1^{\text {st }}$ edition published by Controller of publications New-Delhi, printed by CSIR, ISCAR, NISCAR, New-Delhi, p. 140-141, 153.

\section{Cite this article as:}

Jagadeesh G Mitti. Different modern techniques used in Churna Kalpana: A Review. Int. J. Res. Ayurveda Pharm. 2020;11(5):140-142 $\quad$ http://dx.doi.org/10.7897/2277every effort has been taken to verify the accuracy of the content published in our Journal. IJRAP cannot accept any responsibility or liability for the site content and articles published. The views expressed in articles by our contributing authors are not necessarily those of IJRAP editor or editorial board members. 